\title{
Awake Retromolar Bonfils Intubation in Patient with Very Low Mouth Opening
}

\author{
Luca Pecora $^{1}$, Stefano Falcetta ${ }^{2 *}$, Mariella Donati ${ }^{1}$, and Paolo Pelaia ${ }^{3}$ \\ ${ }^{I}$ Anesthesia and Intensive Care Unit, Department of Emergency, Ospedali Riuniti, Ancona, Italy \\ ${ }^{2}$ Clinic of Anesthesia and Intensive Care Unit, Department of Emergency, Ospedali Riuniti, Ancona, Italy \\ ${ }^{3}$ Clinic of Anesthesia and Intensive Care Unit, Department of Neuroscience, Università Politecnica delle Marche, Ancona, Italy
}

${ }^{*}$ Corresponding author: Stefano Falcetta, Clinic of Anesthesia and Citation: Citation: Pecora L, Falcetta S, Donati M, Pelaia P (2016) Awake Intensive Care Unit, Departiment of Emergency, Ospedali Riuniti Ancona Retromolar Bonfils Intubation in Patient with Very Low Mouth Opening. 60126, Via Conca 71 Ancona, Italy, Tel: 3479639676 -0731 214278; E-mail: Enliven: J Anesthesiol Crit Care Med 3(3): 006.

falmed@libero.it

Received Date: $29^{\text {th }}$ October 2016

Accepted Date: $18^{\text {th }}$ November 2016

Published Date: $22^{\text {nd }}$ November 2016

\begin{abstract}
Copyright: 2016 Dr. Stefano Falcetta. This is an Open Access article published and distributed under the terms of the Creative Commons Attribution License, which permits unrestricted use, distribution and reproduction in any medium, provided the original author and source are credited.
\end{abstract}

\begin{abstract}
According to the Italian Society of Anesthesiology (SIAARTI) guidelines, an awake fiberoptic intubation is the gold standard to manage a predicted difficult airway. At our institution, we are experienced in the use of the Bonfils Fiberscope ${ }^{\circledR}$ (Karl Storz), a rigid fiber optic metallic stylet, to intubate patients with expected difficult airways as well as patients with unexpected difficult airways after failed direct laryngoscopic intubation. We performed an awake retromolar fiber optic intubation in a 42-yr-old man with a temporo-mandibular anchilosis, with a very low mouth opening, with a Mallampati class 4 and an interincisor distance of $1,2 \mathrm{~cm}$. A conscious sedation was performed by the administration of i.v. midazolam $0.03 \mathrm{mg} / \mathrm{kg}$ and fentanyl 2 $\mathrm{mcg} / \mathrm{kg}$. The topical anesthesia consisted in the administration of lidocaine spray $10 \%$ puffs in the oral cavity, in particular in the right vestibule with the adjunct of an instillation of lidocaine $1 \%$ on the glottis aditus through an atomizer (Optispray ${ }^{\circledR}$ ) under endoscopic vision. The retromolar approach is the method of choice in patients with limited mouth opening compared to the paraglossic technique; since the device is introduced laterally in the vestibule of the oral cavity, it can be well tolerated by the patient.
\end{abstract}

Keywords: Intubation; Difficult airway; Limited mouth opening

\section{Introduction}

According to the Italian Society of Anesthesiology (SIAARTI) guidelines, an awake fiber optic intubation is the gold standard to manage a predicted difficult airway [1]. Although an awake fiber optic intubation is traditionally performed by flexible bronchoscope, within the last decade many new devices have been used in anticipated difficult airway, such as video laryngoscopes [2,3] and rigid fiber optic stylets [4,5]. At our institution, we are experienced in the use of the Bonfils Fiberscope ${ }^{\circledR}$ (Karl Storz), a rigid fiber optic metallic stylet, with an external diameter of $5.0 \mathrm{~mm}$ and a fixed 40 degrees curvature, to intubate patients with expected difficult airways as well as patients with unexpected difficult airways after failed direct laryngoscopic intubation.

\section{Case Presentation}

We performed an awake retromolar fiberoptic intubation in a 42-yr-old man with a temporo-mandibular anchilosis (Figure 1), who underwent to a lumbar vertebral fixation of L4-L5 fracture in a prone position. His airway examination revealed a Mallampati class 4, an interincisor distance of $1,2 \mathrm{~cm}$ and a thyromental distance of 3,0 cm (Figure 1). On arrival in the operating room, nasal oxygen (12 1/min), and routine monitoring will be established. A conscious sedation was performed by the administration of i.v. midazolam $0.03 \mathrm{mg} / \mathrm{kg}$ and fentanyl $2 \mathrm{mcg} / \mathrm{kg}$. The endoscopist provided topical anesthesia by the administration of lidocaine spray $10 \%$ puffs in the oral cavity, in particular in the right vestibule. After slightly opening the mouth, the device was introduced into the right side of the oral cavity's vestibule and, sliding behind the molars, it was advanced along the pharyngeal wall. At the pharyngeal posterior wall (tonsil pillar), the device's distal extremity was rotated in an anterior and caudal direction up to visualize the epiglottis. Then it was advanced toward the vocal cords lifting the epiglottis. After applying an instillation of lidocaine $1 \%$ on the glottis aditus through an atomizer (Optispray ${ }^{\circledR}$ ) under endoscopic vision, the fiberscope was left in position and the mounted tube, was railroaded over it with a gentle rotation to be inserted into the trachea. Then a routine IV anesthesia induction was performed. The intubation procedure took less than 1 minute and no complications occurred. 


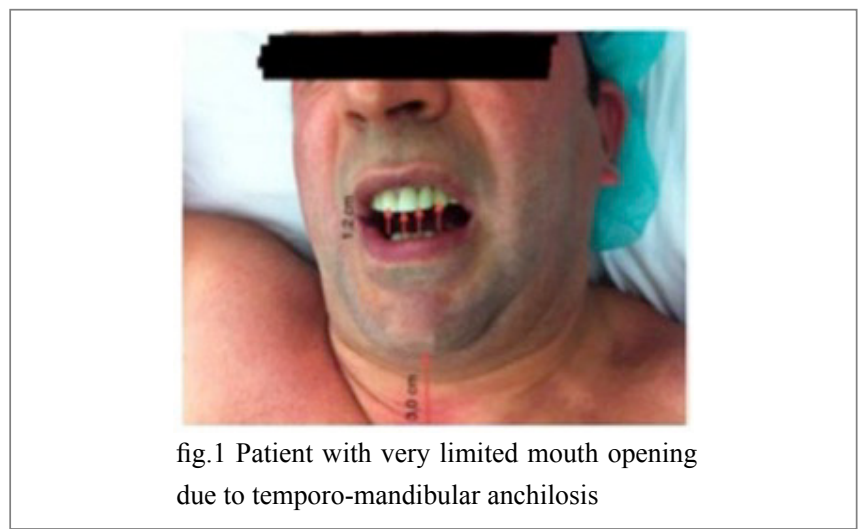

Discussion

To date there are very few reports of the Bonfils as a device to perform awake intubation in expected difficult airway [3-6]. As well reported [5-8] the retromolar Bonfils intubation technique can be very helpful in patients with low mouth opening or limited neck mobility. It has been demonstrated that the Bonfils is an efficacy and atraumatic device for difficult airway management [7]. In case of limited mouth opening it may be easier introduced in the oral cavity than a video laryngoscope or LMA due to its slenderness $[5,6]$. Steven et al. [4] in 2008 used the Bonfils fiberscope in a $2 \mathrm{~cm}$ mouth opening patient, while Nabil et al. [6] described its efficacy for the intubation in $1,5 \mathrm{~cm}$ mouth opening. Compared to the flexible bronchoscope it can better navigate through soft tissues even in patients with large tongue or large tonsils and its rigid structure allows a large floppy epiglottis to be physically lifted. The Bonfils may be easier to use as demonstrated by its learning curve [8]. Nevertheless, skill should be obtained before its use in difficult situations, so it is reasonable to practice before on patients with normal airways under general anesthesia. The Bonfils is more affordable, durable, earlier available and easier to clean then the flexible fiberscope, but it cannot be used for nasotracheal intubation. When using the Bonfils for an awake intubation, patient's preparation must be planned with great care, providing for slight sedation, maintaining the spontaneous breathing and applying an effective local anesthesia. The retromolar approach (Figure 2,3) is the method of choice in patients with limited mouth opening compared to the paraglossic technique [8]; since the device is introduced laterally in the vestibule of the oral cavity, it can be well tolerated by the patient. We think that the Bonfils fiberscope can be helpful for an awake fiber optic intubation in very limited mouth opening and it should be considered as an effective tool as well the flexible bronchoscope. Nevertheless further studies have to be done and actually, the flexible fiberscope still remains the gold standard in anticipated difficult airways.

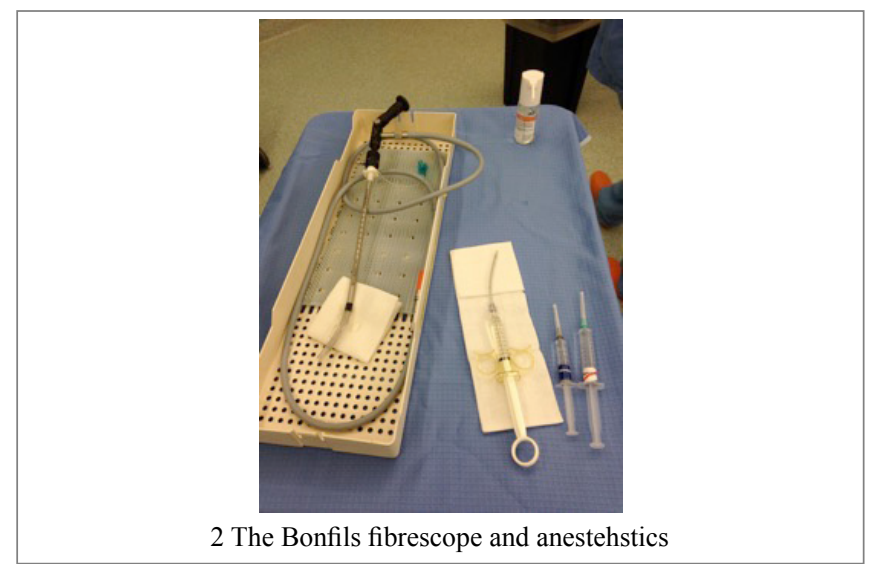

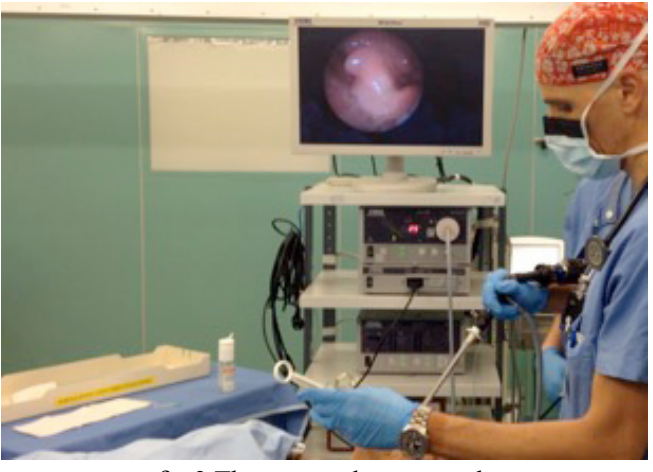

fig.3 The retromolar approach

\section{References}

1. Petrini F, Accorsi A, Adrario E, Agrò F, Amicucci G, et al. (2005) Recommendations for airway control and difficult airway management. Minerva Anestesiol 71: 617-657.

2. Serocki G, Neumann T, Scharf E, Dörges V, Cavus E (2013) Indirect videolaryngoscopy with C-MAC D-Blade and GlideScope: a randomized, controlled comparison in patients with suspected difficult airways. Minerva Anestesiol 79: 121-129.

3. Moore AR, Schricker T, Court O (2012) Awake videolaryngoscopyassisted tracheal intubation of the morbidly obese. Anaesthesia 67: 232235.

4. Steven IA, Allen AH, Carin AH (2008) Awake insertion of the Bonfils Retromolar Intubation Fiberscope in five patients with anticipated difficult airways. Anesth Analg 106: 1215-1217.

5. Corbanese U, Possamai C (2009) Awake intubation with the Bonfils fibrescope in patients with difficult airway. Eur J Anaesthesiol 26: 837841.

6. Shollik NA, Ibrahim SM, Ismael A, Agnoletti V, Piraccini E, et al. (2012) Use of the Bonfils Intubation Fiberscope in Patients with Limited Mouth Opening. Case Rep Anesthesiol 2012: 297306.

7. Rudolph C, Schneider JP, Wallenborn J, Schaffranietz L (2005) Movement of the upper cervical spine during laryngoscopy: a comparison of the Bonfils intubation fibrescope and the Macintosh laryngoscope. Anaesthesia 60: 668-672.

8. Falcetta S, Pecora L, Orsetti G, Gentili P, Rossi A, et al. (2012) The Bonfils fiberscope: a clinical evaluation of its learning curve and efficacy in difficult airway management. Minerva Anestesiol 78: 176-184.

Submit your manuscript at

http://enlivenarchive.org/submit-manuscript.php

New initiative of Enliven Archive

Apart from providing HTML, PDF versions; we also provide video version and deposit the videos in about 15 freely accessible social network sites that promote videos which in turn will aid in rapid circulation of articles published with us. 